\title{
De la función endocrina a la biología molecular. Comentarios a propósito del lanzamiento del libro Fisiología Endocrina, 4a. Edición.
}

\section{Alfredo Jácome Roca}

Internista-Endocrinólogo, Miembro Honorario de la ACE, Editor de la Fisiología Endocrina, $4^{a}$. Edición.

Fecha de recepción: 31/07/2017

Fecha de aceptación: 6/08/2017

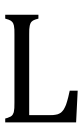

a Asociación Colombiana de Endocrinología, Diabetes y Metabolismo y la Editorial Manual Moderno, han publicado la 4⿳ạ. Edición de Fisiología Endocrina. Las dos primeras ediciones (1972 y 1979) fueron publicadas por la Editorial El Ateneo de Buenos Aires, y la tercera (2005) por la Academia Nacional de Medicina. La actual edición fue escrita por 23 autores, la mayoría miembros de la ACE, y tiene 460 páginas, 18 capítulos, secciones de objetivos, resumen, historia, siglario (un glosario y un índice temático al final), además de la información en sí, donde en cada capítulo usualmente se describe la filogenia, embriología, anatomía, histología, fisiología propiamente dicha, enfermedades relevantes de cada órgano, referencias citadas en el texto, y numerosas figuras, tablas y algunas fotografías. La edición fue realizada a 2 colores. Como editores asociados figuran los endocrinólogos Enrique Ardila y Luz Ángela Casas.

Si leemos el presente texto, podríamos creer que ya se sabe todo sobre el tema. No es así: próximas ediciones, probablemente a cargo de otros endocrinólogos, ojalá de diferentes países, mostrarán nuevos conceptos, nuevos horizontes y nuevos fármacos de la cambiante signalogía celular -para llamar de otra manera a la fisiología endocrina-, ciencia en constante evolución al servicio no ya de un mundo, sino de un universo maravilloso que nos hace pensar que vivimos en una etapa de ciencia-ficción. Los endocrinólogos nos encargaremos de mantener ancianos felices y saludables, algo que no encontró Ponce de León en su búsqueda de la fuente de la eterna juventud.

En 1716, la Academia de Ciencias de Burdeos instituyó un concurso para premiar el trabajo que aclarara la función de las cápsulas suprarrenales; encargado de valorar dichas memorias, el Barón de Montesquieu tuvo que declararlo desierto. "Tal vez con el tiempo, el azar aclare la respuesta", dijo. Tres siglos más tarde, el conocimiento de las glándulas sin conducto o de secreción interna, ha progresado exponencialmente hacia una ciencia que podríamos llamar la "hormonómica".

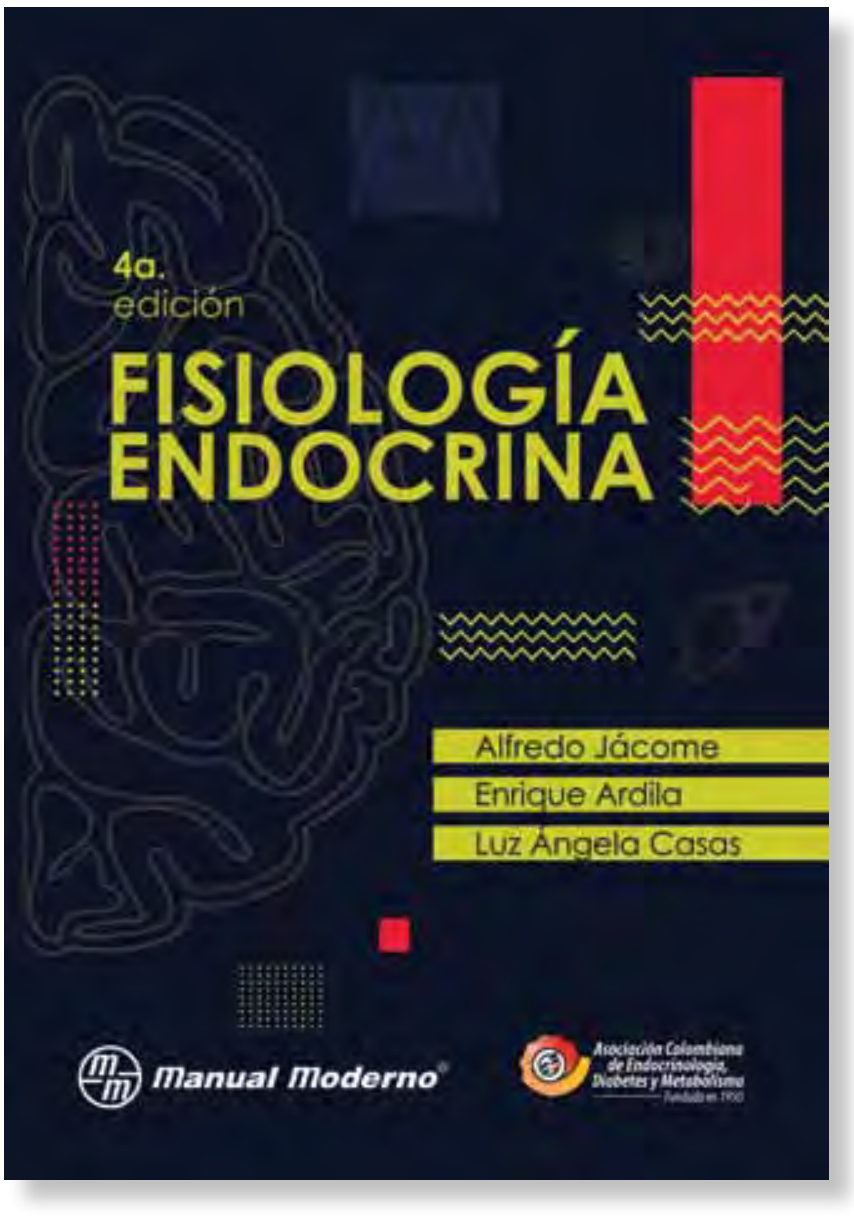

Estudiosos de variada naturaleza contribuyeron al desarrollo de la endocrinología, pero de especial connotación fueron los hallazgos de los fisiólogos. Para la misma época en que Addison describió la enfermedad, Berthold observó que la cresta del gallo era andrógeno-dependiente, pues al castrarlo y luego implantarle los testículos en la cavidad abdominal, no se producían los signos del gallo capón. Oliver y Schaffer encontraron la epinefrina, al inducir hipertensión en un perro tras la administración de extracto suprarrenal. En 1902, Bayliss y Sterling descubrieron la secretina, molécula que dio inicio a la endocrinología, al proponerse el término "hormona", 
mensajero químico que lleva señales de una célula secretora por el torrente sanguíneo a distancia, o entre dos células por el líquido extracelular, para que receptores presentes en una o varias partes de la célula efectora se encarguen de traducir la instrucción recibida.

También hubo experimentos fisiológicos: las pancreatectomías de Minkowski para producir perros diabéticos, el retroceso de la hiperglicemia con el uso de extractos pancreáticos que contenían insulina por Banting y Best, y el efecto diabetógeno de la hipófisis, por Houssay.

La destrucción de la glándula sin conducto generaba la hipofunción, que se corregía con la terapia sustitutiva. Las diferentes hormonas se fueron aislando, se conocieron sus estructuras y, posteriormente, fue posible sintetizar bien las originales o sus análogos. Para los años cincuenta ya era claro que el control de estas secreciones internas se lograba por un mecanismo de retroalimentación.

Las funciones generales que regulan las hormonas son:

1. Crecimiento. Velocidad de crecimiento lineal, aumento de masa ósea y muscular.

2. Diferenciación sexual. Caracteres sexuales secundarios, influyendo también en los primarios.

3. Espermatogénesis, ciclo menstrual, ovulación, embarazo y lactancia.

4. Homeostasis o equilibrio del medio interno, volumen extracelular, tensión arterial, equilibrio electrolítico y de iones plasmáticos como calcio y fósforo.

5. Suministro de energía. Mantenimiento de reservas energéticas, distribución y gasto de calorías.

6. Conducta. Ingestión de agua y alimentos, líbido, estado de lucha o de huída, estado de ánimo

7. Pigmentación. De especial importancia en animales.

El concepto que manejaron los primeros endocrinólogos era de gran simplicidad: cada glándula producía su propia hormona, con su especial efecto, presentando además dicho órgano secretor una enfermedad por deficiencia o por exceso, con manifestaciones sistémicas. Hoy tenemos un panorama complejo: determinado tejido produce varias hormonas, ya que tiene distintas células; una hormona también es producida en diferentes tejidos; dicha señal puede ligarse a receptores en diferentes partes, y esos receptores pueden recibir diferentes ligandos. La farmacología reversa permite la interacción de "péptidos de librería" con receptores huérfanos (así se descubrió la Gh-relina u hormona del hambre); y los estudios de genoma completo permiten ver acciones en genes distintos a los clásicamente modificados por una señal hormonal dada; por ejemplo, probablemente hay diferencias sutiles entre la acción nuclear de los esteroides y los de las hormonas tiroideas. Una nueva hormona, la tiroestimulina — similar a la tirotropina o TSH - actúa en el ovario para la maduración del folículo y ofrece un nuevo método para tratar la anovulación de los ovarios poliquísticos.
La endocrinología comparada nos muestra hormonas en organismos multicelulares primitivos, pues no están confinadas al torrente circulatorio. En vertebrados y mamíferos con circulación, ya vemos tejidos endocrinos similares a los del humano. Los estudiosos de este campo investigan la evolución de dichos sistemas y su papel en la adaptación de los diferentes animales a su medio ambiente y en la producción de sus crías. Ya se habla de una endocrinología de los mamíferos, de cómo existían hormonas en peces que luego se encontraron en vertebrados (por ejemplo, la prolactina como controladora del metabolismo hidroelectrolítico, la maduración paracrina de los oocitos, o el efecto de las hormonas tiroideas en los embriones de renacuajos). Los receptores de estrógenos y progesterona en el oviducto de los pollos, facilitaron un modelo de investigación para el estudio de las acciones esteroideas en los humanos.

Existe ahora una clasificación más amplia de los mediadores químicos, pues la signalogía celular no es solo glandular o por hormonas clásicas. También están los neurotransmisores sinápticos, los segundos mensajeros intracelulares, los neuromoduladores, las neurohormonas o neurosecreciones, las hormonas locales y las feromonas (muy importantes en animales no humanos). Es decir, en sentido amplio, los procesos hormonales tienen funciones no solo endocrinas (a distancia), sino también paracrinas (a células vecinas), autocrinas (dentro de la misma célula), intracrinas (una hormona se transforma citosólicamente en otra, con nuevos efectos) y yuxtacrinas (contacto de una célula con la matriz celular de otra, por medio de moléculas de adhesión). También se conoce el término "neuroendocrino", para referirse a las secreciones por neuronas peptidérgicas. Citando el prólogo de Luz Ángela Casas, hoy tenemos "semejanzas de las hormonas con neurotransmisores y con citocinas; descubrimiento de nuevas hormonas, nuevos mecanismos de acción, receptores, señalización; la influencia del medio ambiente sobre los genes y la disrupción endocrina; todo esto hace parte del amplio panorama de la fisiología endocrina, lo que facilita el entendimiento fisiopatológico de sus enfermedades o disfunciones".

La función del sistema endocrino es coordinar e integrar la actividad celular del organismo, con el fin de mantener la homeostasis. Es armonizador funcional de los diferentes órganos y, además, se encarga de la relación del organismo con el entorno. El clínico debe conocer esta fisiología para entender los mecanismos de la enfermedad endocrina, los procesos diagnósticos y los nuevos tratamientos.

Confiamos en el éxito de esta 4 a edición, que servirá a numerosos estudiantes de las ciencias de la vida, tanto en Colombia como en Latinoamérica. A partir de la presente edición, la Asociación Colombiana de Endocrinología, Diabetes y Metabolismo habrá de encargarse de futuras ediciones, en la que participarán nuevos autores, posiblemente también de fuera de Colombia. 